\title{
UPAYA PEMANFAATKAN SUMBER DAYA ALAM DALAM MENJAGA KEBERSIHAN LINGKUNGAN DI DESA MAMBULILLING, KECAMATAN MAMASA
}

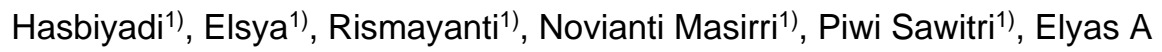 \\ 1)Program Studi Manajemen,STIEM Bongaya Makassar, Makasar, Sulawesi Selatan, Indonesia
}

Corresponding author : Hasbiyadi

E-mail : elsyaelshy12@gmail.com

Diterima 03 November 2020, Direvisi 13 November 2020, Disetujui 13 November 2020

\begin{abstract}
ABSTRAK
Kebersihan lingkungan merupakan pintu gerbang dalam mencapai hidup yang sehat. Kesadaran tentang pengetahuan hidup bersih dan sehat sangat penting dan sehat sangat penting bagi masyarakat yang ada diperkotaan maupun pedesaan. Kurangnya kesadaran masyarakat untuk menjaga kebersihan lingkungan di desa mambulilling masih sangat rendah diamati dari sampah yang berserakan dilingkungan serta tidak tersedianya tempat sampah dirumah maupun ditempat umum. Dengan adanya program pengabdian masyarakat ini bertujuan untuk menambah pengetahuan serta meningkatkan kesadaran masyarakat untuk membuang sampah pada tempatnya serta mengajarkan membuat tempat sampah dari bambu dengan memamfaatkan sumber daya alam yaitu bambu. Kegiatan pengabdian pada masyarakat ini dalam penyampainnya menggunakan metode diskusi, penyuluhan dan aksi lapangan. Hasil dari pengabdian ini yaitu bertambahnya wawasan masyarakat mengenai manfaat dan dampak-dampak buruk dari membuang sampah sembarangan sehingga masyarakat mulai berkomunikasi untuk menjaga tempat tinggal mereka. Sampah merupakan bagian dari kehidupan manusia. Sampah adalah benda/zat sisa yang sudah tidak terpakai. Seharusnya sampah mendapat perhatian dan penanganan yang serius. Namun karena kurangnya pengertian masyarakat desa mambulilling dan pemerintah, setempat, juga kurangnya biaya dan pendapatan sebagian besar masyarakat desa mambulilling, maka masalah sampah ini menjadi terabaikan. Saat ini sebagian masyarakat telah mengetahui dampak buruk sampah, antara lain menyebakan banjir, penyakit dan bau yang dapat mengganggu kehidupan, tapi hal ini tidak diimbangi oleh perilaku masyarakatnya sendiri.
\end{abstract}

Kata kunci: sehat; bersih; sampah.

\begin{abstract}
Environmental cleanliness is the gateway to achieving a healthy life. Awareness of the knowledge of clean and healthy living is very important and very important for people in urban and rural areas. The lack of public awareness to maintain environmental cleanliness in the village of Mambulilling is still very low, observed from the garbage scattered around the environment and the unavailability of trash bins at home or in public places. With this community service program, it aims to increase knowledge and increase public awareness to dispose of waste in its place and teach how to make bamboo trash cans by utilizing natural resources, namely bamboo. In its delivery, this community service activity uses the method of discussion, counseling and field action. The result of this service is increasing public insight about the benefits and bad effects of littering so that people begin to communicate to protect their place of residence. Garbage is a part of human life. Garbage is an unused waste object / substance. Garbage should get serious attention and handling. However, due to the lack of understanding of the Mambulilling village community and the local government, as well as the lack of funds and income for most of the Mambulilling village community, this waste problem has been neglected. Currently, some people are aware of the bad effects of waste, including flooding, disease and odors that can disrupt life, but this is not offset by the behavior of the community itself.
\end{abstract}

Key words: healthy; clean; trash.

\section{PENDAHULUAN}

Sampah merupakan salah satu faktor yang menyebabkan rusaknya lingkungan hidup. Sampah adalah material yang dibuang sebagai sisa dari hasil produksi industri maupun rumah tangga. Sampah adalah suatu bahan yang terbuang atau dibuang, merupakan hasil aktifitas manusia maupun alam yang sudah tidak digunakan lagi karena sudah diambil unsur atau fungsi utamanya. Setiap aktifitas manusia pasti menghasilkan buangan atau sampah. Sumber sampah bias berasal dari 
rumah tangga, pertanian, perkantoran, perusahaan, rumah sakit, pasar dan sebagainya (Sejati, 2009) .

Permasalahan mengenai sampah membutuhkan perhatian yang lebih dari berbagai pihak, baik dari pemerintah maupun masyarakat sekitar. Sampai saat ini persoalan mengenai sampah belum bisa terselesaikan.

Laju pertumbuhan penduduk saat ini memicu semakin meningkatnya produksi sampah ke lingkungan. Sampah yang tidak terkelola, selain menimbulkan bau tidak sedap dan mengganggu estetika, juga menjadi media perkembang biakan vektor dan hewan pengerat. Sampah tidak ditangani dengan baik akan berimbas pada menurunnya kualitas kehidupan, keindahan lingkungan,potensi terjadi banjir akan lebih besar karena tidak menutup kemungkinan sampah area tersebut akan menghalangi arus air sehingga terjadi bencana alam seprti banjir dan menurunnya kualitas kesehatan warga masyarakat yang tinggal di sekitar area polusi sampah.

Penumpukan sampah disebabkan oleh beberapa faktor, diantaranya adalah volume sampah yang sangat besar sehingga malebihi kapasitas daya tampung. tempat pembuangan sampah akhir (TPA). Pengelolaan sampah yang terjadi selama ini dirasakan tidak memberikan dampak positif kepada lingkungan, dan kuranganya dukungan kebijakan dari pemerintah. Menurut Prof. Dr. Ir. Ign. Suhatro dalam buku Limbah Kimia (2011) mengatakan pemerintah belum begitu serius dalam memikirkan masalah sampah ini. Meski pemerintah sudah melakukan beberapa terobosan namun di beberapa tempat pembuangan sementara (TPS) gunungan sampah masih sangat mengganggu masyarakat dan masih menjadi perhatian. Sampah yang terus bertambah dan tidak dikelola dengan baik dapat menimbulkan masalah baik pada pemerintah, sosial masyarakat, kesehatan dan lingkungan (Mulasari dan Sulistyawati, 2014). Sampah yang tidak ditangani sebagaimana mestinya akan menimbulkan berbagai dampak negatif. Dari segi kesehatan dapat menyebabkan timbulnya berbagai jenis penyakit.

Persoalan sampah saat ini tidak hanya menjadi permasalahan di kota-kota besar saja, melainkan juga di desa-desa. Kebiasaan membuang sampah sembarangan dilakukan hampir di semua kalangan masyarakat, tidak hanya warga miskin, bahkan mereka yang berpendidikan tinggi juga melakukannya. Ini sangat menyedihkan karena minimnya pengetahuan tentang sampah dan dampaknya. Perilaku buruk ini semakin menjadi karena minimnya sarana kebersihan yang mudah dijangkau oleh masyarakat di tempat umum (Kartiadi, 2009 dalam Mulasari dan Sulistyawati 2014).

Hal tersebut juga terjadi di Desa Mambulilling. Sampah-sampah banyak ditemukan di tempat umum seperti sekolah, kantor desa bahkan di sepanjang jalan penghubung abtar dusun di desa ini.

Desa Mambulilling merupakan salah satu desa yang terletak di Kecamatan Mamasa, Kabupaten Mamasa, Provinsi Sulawesi Barat. awalnya Desa Mambulilling merupakan kampung tua yang diberi nama Loko kemudian pada tahun 1998 dimekarkan menjadi satu desa yang diberi nama Desa Mambulilling,pemberian nama Desa Mambulliling ini karena desa mambulling tepat berada di bawah Gunung Mambulling atau sering disebut berada di bawah kaki Gunung Mambulilling. Secara geografis terletak berbatasan.

1) Sebelah Utara berbatasan dengan Hutan Lindung

2) Seblah Timur berbatasan dengan Desa Tondok bakaru

3) Sebelah Selatan berbatasan dengan Desa Buntu Buda

4) Sebelah Barat berbatasan dengan Desa Taupe

Desa Mambulilling memiliki topografi berbukit-bukit, dengan kondisi jalan naik turun berkelok-kelok, kanan kiri jalan adalah bukitbukit dan ladang dengan hasil pertanian berupa padi, sayur, dan bambu. Berdasarkan observasi di lapangan ditemukan bahwa kesadaran masyarakat akan pentingnya kebersihan lingkungan masih sangat kurang. Hal ini terlihat dari banyak sampah - sampah yang berserakan di pinggir jalan, dan ada juga yang membuang sampah di sungai dan selokan. Disepanjang jalan desa tersebut tidak ditemukan tempat sampah, baik rumah-rumah maupun tempat umum seperti kantor di desa dan di tempat ibadah.

Dari hasil observasi kami menemukan pokok permasalahannya yaitu;

1. Kurangnya kesadaran masyarakat akan kebersihan lingkungan

2. Kurangnya pemahaman masyarakat akan dampak penyakit akibat membuang sampah sembarangan

3. Kurangnya fasilitas (tempat sampah) terutama di tempat umum seperti kantor desa dan tempat ibadah

Berdasarkan permasalahan tersebut, maka dalam program pengabdian ini kami memanfaatkan sumber daya alam yang ada di desa Mambulilling untuk mengolah pohon bambu menjadi tempat sampah. Tujuan 
program ini agar masyarakat dapat menjaga kebersihan lingkungan sekitar, terutama ditempat-tempat ibadah. program ini juga dapat menambah wawasan masyarakat akan pentingnya lingkungan yang bersih dan bebas sampah. Dengan tersedianya tempat sampah maka akan dapat mengurangi kebiasaan membuang sampah di sembarang tempat sehingga dapat meningkatkan kebersihan lingkungan untuk peningkatan kesehatan masyarakat apalagi di masa sekarang ini yang lagi di serang pandemi covid-19. Sampah yang berserakan di pinggir jalan dan belakang rumah masyarakat dapat di lihat pada gambar 1 dan 2.

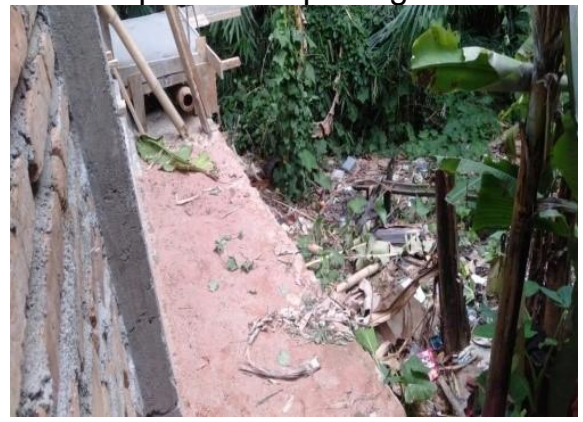

Gambar 1. Sampah yang berserakan di belakang rumah masyarakat

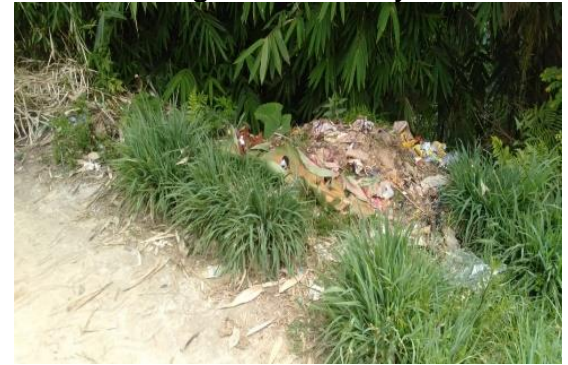

Gambar 2. Sampah yang berserakan di pinggir jalan

\section{METODE}

Pelaksanaan program pengabdian masyarakat dilaksanakan di Desa Mambuliling, Kecamatan mamasa, kabupaten Mamasa, Sulawei Barat. yang menjadi mitra dalam melaksanakan program pengabdian ini yaitu pemerintah dalam hal ini kepala Desa bersama aparat desa lainnya. Pada tanggal 15 Juli - 05 Agustus 2020.

Pemecahan masalah yang dilaksanakan pada kegiatan pengabdian ini yaitu memberikan edukasi kepada masyarakat mengenai dampak buruk yang akan timbul jika membuang sampah sembarangan, seperti dampak bagi bagi lingkungan dan terhadap keadaan sosial ekonomi, selain itu membuang sampah sembarangan juga dapat berdampak buruk bagi kesehatan, terutama dapat menimbulkan penyakit seperti penyakit diare, tifus, jamur, dan cacing pita.

Selain memberikan pemahaman kemasyarakat tentang dampak membuang sampah sembarangan, kami juga memberikan solusi yaitu dengan membuat tempat sampah dengan dari bahan alam yang tersedia di Desa Mambulilling tersebut

Tahapan dalam pengabdian ini yaitu sebagai berikut ;

a. Kunjungan kelokasi pengabdian untuk menganalisa kondisi lingkungan

b. Melakukan survei ke alam sekitar untuk melihat apa saja hasil alam yang dapat dijadikan sebagai bahan pembuatan tempat sampah.

c. Dari hasil analisis dan survey dilakukan koordinasi dengan Aparat desa untuk mempersiapkan kegiatan selanjutnya

d. Persiapan bahan dan alat pelatihan praktek pembuatan tempat sampah bambu

e. Pembagian tempat sampah .

\section{HASIL DAN PEMBAHASAN}

Sebagai tindak lanjut dari indentifikasi permasalahan mengenai pembuangan sampah maka Mahasiswa program pengabdian Masyarakat STIEM Bongaya angkatan XLI Tahun akademik 2019/2020-2 mengadakan kegiatan program kerja inti sebagai bagian dari rangkaian kegiatan pengabdian masyarakat di Desa Mambulilling, Kecamatan Mamasa, Kabupaten Mamasa. Kegiatan ini dilaksanakan pada hari Rabu 15 Juli 2020 - 05 Agustus 2020.

Dalam pembuatan tempat sampah ini kami membutuhkan peralatan seperti, gergaji dan palu, sedangkan bahan yang di butuhkan yaitu, bambu, balok, dan paku. Pembuatan tempat sampah yang dilaksanakan membutuhkan waktu selama 2 minggu, Mulai dari proses pengambilan bahan, sampai pengecetan. Dalam proses pengambilan Bambu dan pembuatan kerangka Tempat Sampah, kami dibantu oleh beberapa masyarakat. Proses pembuatan tempat sampah ini melibatkan partisipasi masyarakat yang berjumlah 15 orang.

Adapun beberapa tahap pembuatan tempat sampah sebagai berikut :

1. Dalam pengambilan bambu, masyarakat ikut membantu memilih dan menebang. Bambu yang digunakan merupakan bambu yang berumur 3-4 tahun, setelah penebangan pohon langkah selanjutnya yang dilakukan yaitu, memotong bambu menjadi potongan-potongan yang berukuran $60 \mathrm{~cm}$, kemudian dibagi lagi menjadi beberapa bagian.

2. Selanjutnya yaitu kerangkat pembuatan tempat sampah yang terbuat dari balok yang dikumpulkan dari sisa-sisa potongan pembuatan rumah mayarakat, yang di potong menjadi $50 \mathrm{~cm}, 40, \mathrm{~cm}$ dan $30 \mathrm{~cm}$. 
kemudian dibentuk menjadi kerangka tempat sampah. Dalam pembuatan karangka ini kami dibantu oleh aparat desa.

3. Kemudian pembuatan tempat sampah, potongan bambu yang telah dibagi menjadi beberapa bagian tadi kemudian dipasang pada karangka untuk dijadikan sebagai dinding/badan tempat sampah, yang dapat dilihat pada gambar 3 dan 4 di bawah ini:

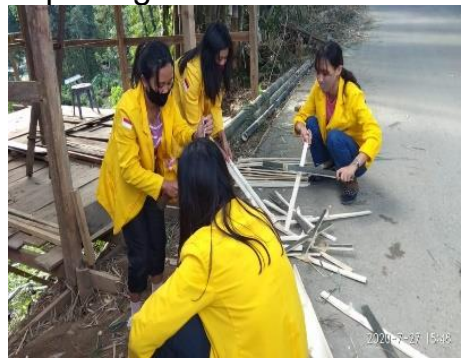

Gambar 3. Pemotongan bambu menjad beberapa bagian

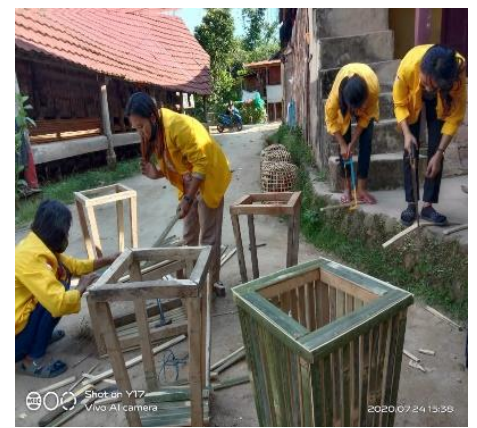

Gambar 4. Pembuatan tempat sampah

4. Langkah terakhir yaitu pengecetan tempat sampah yang disesuaikan dengan warna almamater kampus yaitu warna kuning

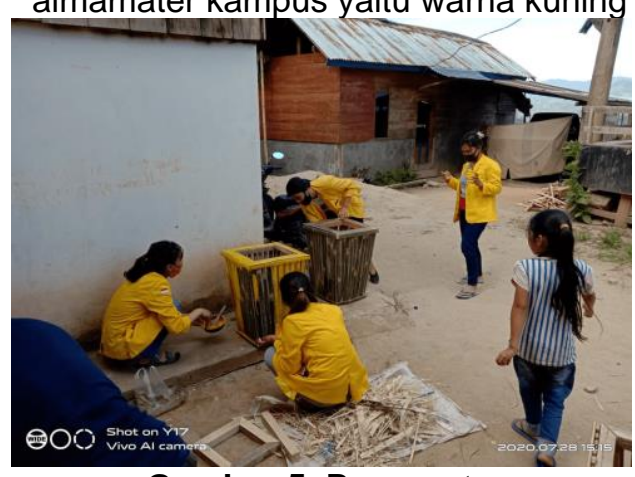

Gambar 5. Pengecatan

Setelah semua kegiatan selesai tahap akhir dari kegiatan kami yaitu membagi-bagi tempat sampah kesetiap tempat ibadah dan tepat umum lainnya.

Tabel 1 merupakan laporan mingguan dari kegiatan pengabdian masyarakat selama 2 bulan di Desa Mambulilling.

Tabel 1. Laporan Kegiatan

\begin{tabular}{|c|c|c|}
\hline Jo. & Kegiatan & Pencapaian \\
\hline 1. & $\begin{array}{l}\text { Melakukan } \\
\text { observasi di } \\
\text { desa } \\
\text { Mambulilling } \\
\text { untuk memantau } \\
\text { kondisi } \\
\text { lingkungan }\end{array}$ & $\begin{array}{l}\text { Dengan } \\
\text { melakukan } \\
\text { observasi kami } \\
\text { dapat } \\
\text { menentukan } \\
\text { strategi untuk } \\
\text { perbaikan } \\
\text { kebersihan } \\
\text { lingkungan }\end{array}$ \\
\hline 2. & $\begin{array}{l}\text { Melakukan } \\
\text { survey ke alam } \\
\text { sekitar untuk } \\
\text { melihat apa saja } \\
\text { hasil alam yang } \\
\text { dapat dijadikan } \\
\text { sebagai bahan } \\
\text { pembuatan } \\
\text { tempat sampah }\end{array}$ & $\begin{array}{l}\text { Dari hasil survei } \\
\text { maka kami } \\
\text { dapat } \\
\text { mengamati } \\
\text { hasil alam yang } \\
\text { ada,dengan } \\
\text { pembuatan } \\
\text { tempat sampah } \\
\text { dari pohon } \\
\text { bambu. }\end{array}$ \\
\hline 3. & $\begin{array}{l}\text { Dari hasil } \\
\text { analisis dan } \\
\text { survey dilakukan } \\
\text { koordinasi } \\
\text { dengan Aparat } \\
\text { desa untuk } \\
\text { mempersiapkan } \\
\text { kegiatan } \\
\text { selanjutnya }\end{array}$ & $\begin{array}{l}\text { Hasil keputusan } \\
\text { dari } \\
\text { musyawarah } \\
\text { dengan aparat } \\
\text { desa } \\
\text { menyetujui } \\
\text { untuk } \\
\text { melakukan } \\
\text { pembuatan } \\
\text { pembuatan } \\
\text { tempat sampah. }\end{array}$ \\
\hline 4. & $\begin{array}{l}\text { Persiapan } \\
\text { bahan dan alat } \\
\text { pelatihan } \\
\text { praktek } \\
\text { pembuatan } \\
\text { tempat sampah } \\
\text { bambu }\end{array}$ & $\begin{array}{l}\text { Dengan adanya } \\
\text { sumber alam } \\
\text { yang melimpah } \\
\text { maka, bahan2 } \\
\text { yang diperlukan } \\
\text { sudah tersedia } \\
\text { di desa } \\
\text { Mambulilling ini }\end{array}$ \\
\hline 5. & $\begin{array}{l}\text { Pemberian } \\
\text { pemahaman } \\
\text { kepada } \\
\text { masyarakat } \\
\text { akan pentingnya } \\
\text { kebersihan } \\
\text { lingkungan }\end{array}$ & $\begin{array}{l}\text { Setelah } \\
\text { memberikan } \\
\text { pemahaman } \\
\text { megenai } \\
\text { pentingnya } \\
\text { kebersihan } \\
\text { lingkungan, } \\
\text { masyarakat di } \\
\text { desa } \\
\text { Mambulilling } \\
\text { mulai } \\
\text { memperhatikan } \\
\text { kebersihan } \\
\text { lingkungan } \\
\text { sekitarnya }\end{array}$ \\
\hline
\end{tabular}


Tabel 1. Laporan Kegiatan

\begin{tabular}{cl}
\hline No. Kegiatan & \multicolumn{1}{c}{ Pencapaian } \\
\hline 6. & Dengan adanya \\
& tempat sampah \\
& yang telah \\
& disediakan, \\
& masyarakat \\
& tidak lagi \\
& membuang \\
& sampah \\
& sembarangan. \\
\hline
\end{tabular}

\section{SIMPULAN DAN SARAN Simpulan}

Kesadaran Individu dan seluruh warga begitu penting dalam menjalankan perubahan pada masalah kebersihan dan keamanan lingkungan, baik terhadap lingkungan alam maupun lingkungan sosial. Melalui program pengabdian masyarakat ini kami memberikan solusi kepada masyarakat dengan membuat tempat sampah dari sebagian sumber daya alam di desa mambulilling yaitu pohon bambu. Dimana dalam pembuatan tempat ini melibatkan partisipasi aktif masyarakat sehingga masyarakat dapat membuka peluang dan menambah wawasan tentang manfaat lain dari pohon bambu, agar sumber daya alam yang ada di desa mambulilling dikembangkan oleh masyarakat setempat secara mandiri.

\section{Saran}

Dengan adanya kegiatan pengabdian kepada masyarakat ini, diharapkan agar model partisipatif ini dapat segera diterapkan yang mampu meningkatkan kerjasama, gotong royong, ketertiban, kemandirian dalam mencapai kebersihan dan keamanan lingkungan serta terciptanya kualitas hidup dengan memanfaatkan, mengembangkan sumber daya alam yang ada di desa mambulilling dan hubungan yang lebih baik dalam bermasyarakat.

\section{UCAPAN TERIMA KASIH}

Kami mengucapkan terima kasih yang sebesar besarnya kepada seluruh pihak yang telah membantu kami dalam proses pelaksanaan kegiatan ini khusunya kepada Bapak Hesron Lullunglangi, S.pt, M.pd selaku Camat mamasa; Bapak Andarias S.IP selaku kepala Desa Mambulilling;Tokoh-tokoh masyarakat dan warga masyarakat desa mambulilling yang telah bersedia menerima dan membantu kami selama melaksanakan program pengabdian masyarakat.

\section{DAFTAR RUJUKAN}

Ahmad, R. (2016). Difusi Inovasi Dalam Meningkatkan Masyarakat Akan
Partisipasi

Kelestarian
Lingkungan. Sosiotes Vol 6, N0.2 November2016.

Iskandar, A. A. (2008). pentingnya memelihara kebersihan dan keamnan lingkungan secara partisipatif demi meingkatkan gotong royong dan kualitas hidup warga. Jurnal Ilmiah Pena Vol.1 Nomor 1 Tahun 2018.

Khairunnisa, Jiwandono, I. S., Nurhasanah, Dewi, N. K., Saputra, H. H., \& Wati, T. L. (2019). kampanye kebersihan lingkungan melalui program kerja bakti membangun desa di lombok utara. Jurnal Pendidikan dan Pengabdian Masyarakat Vol. 2 No. 2, Mei 2019 , 2614-7939.

Manurung, E. M., Djelantik, S., \& Indraswari. (2019). film sebagai media media edukasi: peningkatan kesadaran masyarakat tentang kebersihan lingkungan. Prosiding PKM-CSR, Vol. 2 (2019) , 2655-3570.

Riswan, Sunoko, H. R., \& Hadiyarto, A. (2011). pengelolaan sampah rumah tangga di kecamatan daha selatan. Jurnal IImu Lingkungan Vol.9, No. 1, April 2011.

nn. (2018, September 24). Dampak Lingkungan Kotor dan Polusi Sampah. Retrieved from Website resmi pemerintah kabupaten buleleng sejahtera, mandiri, integrasi, lestari, etika: https://bulelengkab.go.id/

Sari, M. M., \& Umama, H. A. (n.d.). Patsambu (Tempat Sampah Bambu) Untuk Peningkatan Kualitas Hidup. kaibon abhinaya: jurnal pengabdian masyarakat, 66 .

asthari, w. (2015, Maret 27). Akibat Membuang Sampah Sembarangan. Retrieved from kompasiana beyond blogging: https://www.kompasiana.com/

Lon, Y. S., Bayu , N. D., Tima, Y., Join, Y. Y., Owa , Y. R., Ndarung , R. A., . . . Wanggus , E. E. (2019). upaya meningkatkan kesadaran masyarakat desa galang. Retrieved from http://repository.stkipsantupaulus.ac.id/

Sahil, J., Muhdar, M. H., Rohman, F., \& Syamsuri, I. (2016). Sistem Pengelolaan dan Upaya Penanggulangan Sampah Di Kelurahan Dufa- Dufa Kota Ternate. jailan dkk, 478. 